\title{
Polymer Surgical Clip Migration Into the Trachea of an Infant
}

\author{
Thomas M. Hagopian, BA, Paula J. Harmon, MD, Matthew S. Clifton, MD \\ Emory University School of Medicine, Atlanta, GA, USA (Hagopian). \\ Division of Pediatric Otolaryngology, Emory University School of Medicine, Atlanta, GA, USA (Dr. Harmon). \\ Division of Pediatric Surgery, Emory University School of Medicine, Atlanta, GA, USA (Dr. Clifton).
}

\begin{abstract}
Introduction: Newborns with congenital esophageal atresia and a distal tracheoesophageal fistula undergo repair by several different approaches, the newest of which is thoracoscopic. The fistula is frequently occluded using a small polymer or titanium clip at the point of insertion into the trachea.

Case Description: We report the case of a 1-day-old male newborn with proximal esophageal atresia and a distal tracheoesophageal fistula who underwent thoracoscopic repair and who then presented with respiratory distress 10 weeks later. The polymer Hem-o-lok clip (Weck Surgical Instruments [Teleflex Medical], Durham, North Carolina) used to ligate the tracheoesophageal fistula eroded through the membranous trachea, causing partial airway obstruction.

Discussion: This case represents a previously unreported complication of the use of polymer clips in esophageal atresia repair. The possibility of airway obstruction after thoracoscopic repair of esophageal atresia with a tracheoesophageal fistula should raise concern among pediatric surgeons and prompt further study into the use of plastic clips for this type of procedure.
\end{abstract}

Key Words: Tracheoesophageal fistula repair, Hem-o-lok clip, Thoracoscopic repair, Clip migration.

Citation Hagopian TM, Harmon PJ, Clifton MS. Polymer surgical clip migration into the trachea of an infant. CRSLS e2014.00360. DOI: 10.4293/CRSLS.2014.00360.

Copyright (C) 2014 SLS This is an open-access article distributed under the terms of the Creative Commons Attribution-Noncommercial-ShareAlike 3.0 Unported license, which permits unrestricted noncommercial use, distribution, and reproduction in any medium, provided the original author and source are credited.

Address correspondence to: Matthew S. Clifton, MD, Division of Pediatric Surgery, Emory University School of Medicine, 1405 Clifton Rd, Atlanta, GA 30322, USA. Telephone: (404) 785-0871, Fax: (404) 785-0800, E-mail: MClifto@Emory.edu

\section{INTRODUCTION}

Congenital tracheoesophageal fistulas (TEFs) are relatively uncommon, with an incidence of 1 in 3500 live births; they commonly occur in conjunction with esophageal atresia (EA). ${ }^{1}$ Minimally invasive repair of these fistulas has gained popularity in the past decade as the treatment for cases of EA and TEF. ${ }^{2}$ During the repair, the distal TEF is identified and is either ligated with sutures or closed with titanium or polymer locking clips before division. Tracheal leak and recurrent fistula formation are rare complications. 3,4

The use of the Hem-o-lok MLK clip (Weck Surgical Instruments [Teleflex Medical], Durham, North Carolina) and other endoscopic clipping devices has risen along with the increase in endoscopic surgery because of their speed and ease of use during endoscopic surgery. Studies have also demonstrated their effectiveness and strength, 5,6 and these devices have gained popularity among urologists for ligation of renal vessels during nephrectomy. ${ }^{7}$ Reported failures of the devices come mostly from laparoscopic urologic and adult general surgery procedures, with the main complication being bleeding. ${ }^{8}$

This is the first report of a patient who underwent repair of EA with a TEF by use of a polymer clip for ligation of the fistula in whom the clip was later found to have eroded through the posterior tracheal wall, causing partial airway obstruction.

\section{CASE DESCRIPTION}

A male patient weighing $2.9 \mathrm{~kg}$ was born at 39 weeks' gestation with several anatomic anomalies including proximal EA with a distal TEF, a secundum-type atrial septal 
defect, a deep sacral pit, and thumb abnormalities. Shortly after the patient's birth, the pediatric surgery department was consulted regarding EA and TEF repair; thoracoscopic repair was performed the next day.

During the operation, the fistula was ligated with a $5-\mathrm{mm}$ Hem-o-lok clip. After application of the clip, it was believed that inadequate occlusion had been obtained, so a figure-of- 8 No. $4-0$ braided absorbable suture was placed on the stump with good occlusion. The esophageal anastomosis was completed in a single-layer end-to-end fashion using interrupted No. 4-0 braided absorbable suture. The remainder of the procedure was performed without complication.

The postoperative course was uncomplicated, with a pullback esophagram obtained on day 5 showing no anastomotic leak. Feeding by mouth was tolerated, and a repeat esophagram obtained on day 20 showed some mild narrowing at the anastomosis site. The patient was discharged on day 21 . On the basis of a report of difficulty swallowing, he returned on day 27 for upper endoscopy and dilation of the stricture, both of which were performed without complication.

At 9 weeks, the patient presented to the emergency department because of choking and concern regarding poor feeding. A repeat esophagram showed normal findings, and the complaints were attributed to reflux. After a brief hospital stay, the patient was sent home with medical management for reflux.

One week later, the patient returned to the emergency department with a complaint of choking while feeding and an episode of cyanosis for $>1$ minute. A pull-back esophagram was obtained to rule out a persistent TEF. This showed nasopharyngeal regurgitation, which prompted an otolaryngology consultation to evaluate the integrity of the palate and larynx. Flexible laryngoscopy showed no cleft. Rigid bronchoscopy showed a foreign body in the mid trachea (Figure 1). The clip had superficial mucosal attachments and was removed from the trachea. No fistula or erosions were noted after removal (Figure 2).

A follow-up esophagram showed negative findings for fistulas, and after an uncomplicated hospital stay, the patient was discharged home with resolution of symptoms.

\section{DISCUSSION}

EA is classified into 5 different types according to the anatomic location of the defect and the presence of a

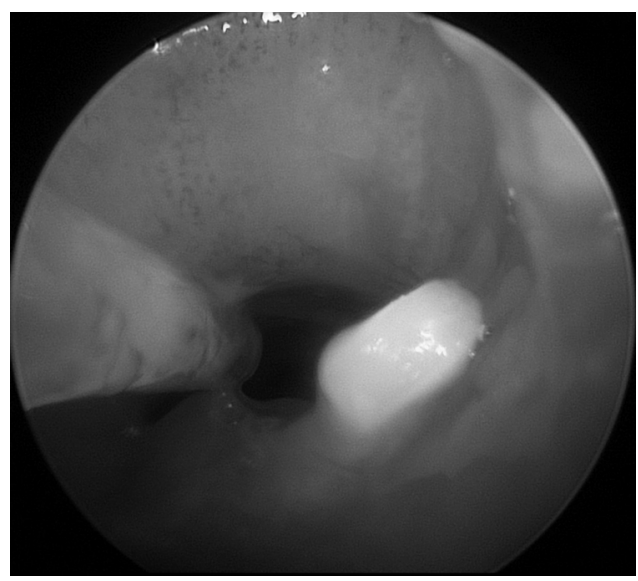

Figure 1. Rigid bronchoscopy showing Hem-o-lok clip with superficial mucosal attachments in posterior mid trachea.

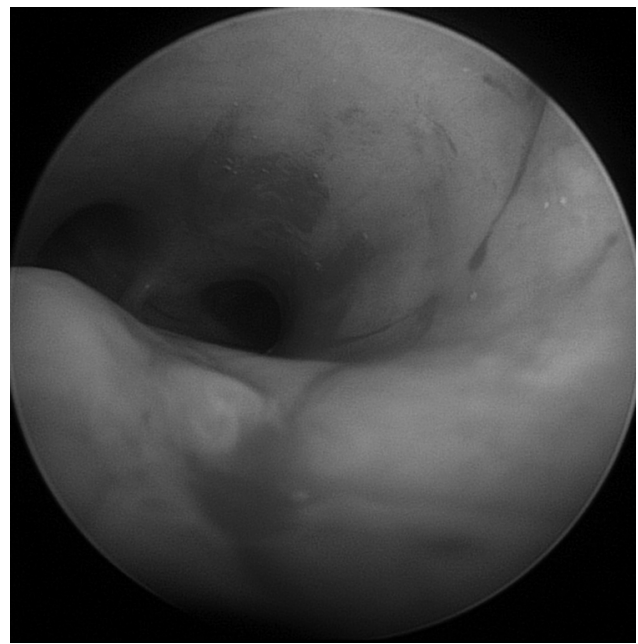

Figure 2. No fistula or erosions were noted after removal of the clip from the trachea.

TEF.9,10 Type $\mathrm{C}$ is the most common (approximately 85\%) and consists of proximal EA and a distal TEF. The treatment is ligation and division of the TEF, followed by a surgical anastomosis of the esophagus.9,11 Type C EA with a TEF necessitates repair shortly after birth, and this can usually be accomplished in a single operation. ${ }^{9}$ The outcomes of minimally invasive repair are generally very favorable for these patients, with the main prognostic determinants of outcome being the presence of other congenital anomalies.12,13 The most frequently reported complications are anastomotic leak (4\%-17\%), esophageal stricture $(8.7 \%-21.4 \%)$, and recurrent fistula formation $(6 \%-10 \%) .^{12,14}$

Whereas the outcomes of thoracoscopic repair are similar to those of open repair, 5 other benefits of a minimally 
invasive approach exist. The main benefit to repairing these defects in a thoracoscopic manner is elimination of the need for a posterolateral thoracotomy, which is associated with significant morbidity as children grow. ${ }^{15}$ There are also cosmetic advantages to the minimally invasive approach in terms of smaller scars. ${ }^{16}$ Other reported benefits include shorter hospital stays ${ }^{17}$ and reduced postoperative pain. ${ }^{18}$

Previous examples of clip migration have been reported in the adult literature related to biliary and urologic surgery. In biliary surgery, clip migration into the common bile duct with subsequent stone formation, ${ }^{8,19}$ as well as migration into the duodenum manifesting as a duodenal ulcer, ${ }^{20-22}$ has been reported. The urology literature describes cases of clip migration into the bladder, rectal migration after robotic prostatectomy, and small bowel obstruction after prostatectomy. ${ }^{23-25}$ Most of these cases involved metallic clips; however, similar complications after migration of polymer Hem-o-lok clips have been observed. ${ }^{26,27}$

The proposed mechanisms of clip migration relate to migration through the cystic duct because most cases are reported after laparoscopic cholecystectomy. Inaccurately placed clips causing damage to the common bile duct, local inflammation and infection, bile leaks, and the use of $>4$ clips during surgery are known risk factors for clip migration. ${ }^{28}$ Migrations tend to occur more frequently when laparoscopic cholecystectomy is performed for acute cholecystitis, supporting a partial inflammatory mechanism for migration. ${ }^{11}$ Nonabsorbable polymer clips have been shown to elicit more inflammation than conventional staples in the appendices of rats, ${ }^{29}$ suggesting that there may be a heightened risk associated with these types of clips, although the incidence of clip migration remains exceedingly rare.

The mechanism of migration in our case remains unclear. An improperly applied clip was not believed to have contributed to the migration because the clip was securely fastened and without signs of failure during the operation. There are no examples of clip migration through the trachea in any discipline, adult or pediatric. If the proposed mechanisms of migration seen in biliary surgery are applicable to this case, it can be hypothesized that an inflammatory reaction created by the presence of a foreign body resulted in clip erosion through the membranous trachea.

The use of endoscopic polymer clips is widely considered safe, simple, and effective. This technique has been used in multiple infants previously without complication. How- ever, this case illustrates a risk of their use that may have disastrous consequences in the newborn patient given the size of the airway. On the basis of the available case studies in the literature, suture ligation of the fistula may prove a better option as a way of avoiding clip-related complications. More study is needed to determine the true frequency of clip migration and the safety of using clips during this operation.

\section{References:}

1. Keckler SJ, St Peter SD, Valusek PA, et al. VACTERL anomalies in patients with esophageal atresia: an updated delineation of the spectrum and review of the literature. Pediatr Surg Int. 2007;23(4):309-313.

2. Tsao K, Lee H. Extrapleural thoracoscopic repair of esophageal atresia with tracheoesophageal fistula. Pediatr Surg Int 2005;21(4):308-310.

3. Patkowsk D, Rysiakiewicz K, Jaworski W, et al. Thoracoscopic repair of tracheoesophageal fistula and esophageal atresia. J Laparoendosc Adv Surg Tech A. 2009;19(Suppl 1):S19-S22.

4. Burford JM, Dassinger MS, Copeland DR, Keller JE, Smith SD. Repair of esophageal atresia with tracheoesophageal fistula via thoracotomy: a contemporary series. Am J Surg. 2011;202(2): 203-206

5. Jellison FC, Baldwin DD, Berger KA, Maynes LJ, Desai PJ. Comparison of nonabsorbable polymer ligating and standard titanium clips with and without a vascular cuff. $J$ Endourol. 2005;19(7):889-893.

6. Joseph J, Leung YY, Eichel L, Scheidweiler K, Erturk E, Wood R. Comparison of the Ti-knot device and Hem-o-lok clips with other devices commonly used for laparoscopic renal-artery ligation. J Endourol. 2004;18(2):163-166.

7. Ponsky L, Cherullo E, Moinzadeh A, et al. The Hem-o-lok clip is safe for laparoscopic nephrectomy: a multi-institutional review. Urology. 2008;71(4):593-596.

8. Meng MV. Reported failures of the polymer self-locking (Hem-o-lok) clip: review of data from the Food and Drug Administration. J Endourol. 2006;20(12):1054-1057.

9. Guidry C, Mcgahren ED. Pediatric chest I: developmental and physiologic conditions for the surgeon. Surg Clin North Am 2012;92(3):615-643; viii.

10. El-Gohary Y, Gittes GK, Tovar JA. Congenital anomalies of the esophagus. Semin Pediatr Surg. 2010;19(3):186-193.

11. Orford J, Cass DT, Glasson MJ. Advances in the treatment of oesophageal atresia over three decades: the 1970s and the 1990s. Pediatr Surg Int. 2004;20(6):402-407. 
12. Rothenberg SS. Thoracoscopic repair of esophageal atresia and tracheoesophageal fistula in neonates, first decade's experience. Dis Esophagus. 2013;26(4):359-364.

13. Konkin DE, O'Hali WA, Webber EM, Blair GK. Outcomes in esophageal atresia and tracheoesophageal fistula. J Pediatr Surg. 2003;38(12):1726-1729.

14. Borruto FA, Impellizzeri P, Montalto AS, et al. Thoracoscopy versus thoracotomy for esophageal atresia and tracheoesophageal fistula repair: review of the literature and meta-analysis. Eur J Pediatr Surg. 2012;22(6):415-419.

15. Jaureguizar E, Vazquez J, Murcia J, Diez Pardo JA. Morbid musculoskeletal sequelae of thoracotomy for tracheoesophageal fistula. J Pediatr Surg. 1985;20(5):511-514.

16. Rothenberg SS. Thoracoscopic repair of esophageal atresia and tracheo-esophageal fistula. Semin Pediatr Surg. 2005; 14(1):2-7.

17. Allal H, Kalfa N, Lopez M, et al. Benefits of the thoracoscopic approach for short- or long-gap esophageal atresia. J Laparoendosc Adv Surg Tech A. 2005;15(6):673-677.

18. Dingemann C, Ure BM. Minimally invasive repair of esophageal atresia: an update. Eur J Pediatr Surg. 2013;23:198-203.

19. Aminian A, Khorgami Z. Hem-O-Lok clip is safe in minimally invasive general surgery: a single center experience and review of data from food and drug administration. J Minim Invasive Surg Sci. 2012;1(2):8-13.

20. Chong VH, Chong CF. Biliary complications secondary to post-cholecystectomy clip migration: a review of 69 cases. $J$ Gastrointest Surg. 2010;14(4):688-696.

21. Wasserberg N, Gal E, Fuko Z, Niv Y, Lelcuk S, Rubin M. Surgical clip found in duodenal ulcer after laparoscopic chole- cystectomy. Surg Laparosc Endosc Percutan Tech. 2003;13(6): 387-388.

22. Samim MM, Armstrong CP. Surgical clip found at duodenal ulcer after laparoscopic cholecystectomy: report of a case. Int J Surg. 2008;6(6):473-474.

23. Hung SF, Chung SD, Wang SM, Jeff Chueh SC, Yu HJ, Lai MK. Bladder migration of Hem-o-Lok clips after laparoscopic radical nephroureterectomy and bladder cuff excision. Surg Laparosc Endosc Percutan Tech. 2011;21(3):e130-e131.

24. Ganpule A, Dhawan DR, Desai MR. Hem-o-Lok clip eroding into the urethra following laparoscopic radical prostatectomy: a case report and review of literature. Indian J Urol. 2010;26(4):580-581.

25. Ghani KR, Hurwitz M, Menon M. Hem-o-lok clip causing small bowel obstruction after robot-assisted radical prostatectomy. Int J Urol. 2012;19(10):962-963.

26. Liu Y, Ji B, Wang Y, Wang G. Hem-o-lok clip found in common bile duct after laparoscopic cholecystectomy and common bile duct exploration: a clinical analysis of 8 cases. Int J Med Sci. 2012;9(3):225-227.

27. Seyyedmajidi M, Hosseini SA, Hajiebrahimi S, Vafaeimanesh J. Hem-o-Lok clip in the first part of duodenum after laparoscopic cholecystectomy. Case Rep Gastrointest Med. 2013;2013:251634.

28. Cetta F, Lombardo F, Baldi C, Cariati A. Clip migration within the common duct after laparoscopic cholecystectomy: a case of transient acute pancreatitis in the absence of associated stones. Endoscopy. 1997;29(9):S59-S60.

29. Delibegović S, Iljazović E, Katica M, Koluh A. Tissue reaction to absorbable endoloop, nonabsorbable titanium staples, and polymer Hem-o-lok clip after laparoscopic appendectomy. JSLS. 2011;15(1):70-76. 